\title{
POESIA CIBORGUE E PÓS-HUMANIZAÇÃO DA LINGUAGEM: DA EXTERNALIZAÇÃO TECNOLÓGICA À RECUPERAÇÃO DA AUTONOMIA HUMANA
}

\section{CYBORG POETRY AND THE POST-HUMANIZATION OF LANGUAGE: FROM TECHNOLOGICAL EXTERNALIZATION TO THE RECOVERY OF HUMAN AGENCY}

\section{Ana Marques}

\section{RESUMO}

Se o pós-humanismo surge hoje como expressão de formas diversas de questionar a excepcionalidade do humano, e se, por outro lado, a linguagem verbal é considerada uma expressão dessa mesma excepcionalidade do humano, a pós-humanização da linguagem revela uma tensão fundamental: entendida enquanto externalização e automação da linguagem verbal por via de dispositivos computacionais (programados para gerar enunciados linguísticos de forma relativamente autónoma), a pós-humanização da linguagem perturba não apenas a centralidade do humano no quadro da tradição iluminista, mas também a noção de que a linguagem verbal é exclusivamente humana. Este artigo reflecte sobre a linguagem gerada por dispositivos computacionais a partir da perspectiva dos estudos literários, e pretende sugerir caminhos de resposta a algumas das questões centrais que emergem do cruzamento entre cibernética, linguagem e literatura. $\mathrm{O}$ que acontece à linguagem quando esta é algoritmicamente processada e gerada? Como podem os processos de representação e produção simbólica ser pensados quando pensamos em agentes linguísticos artificiais? Em que circunstâncias podemos considerar que um texto gerado automaticamente é um poema? Através da análise de uma experiência poética que podemos adjectivar de póshumana, no sentido em que faz uso de ferramentas e processos de geração automática de linguagem, evidenciaremos algumas das tensões entre os dispositivos computacionais e a escrita autoral, interrogando a possibilidade ou a imposibilidade de o literário se inscrever no campo cibernético da automação e demonstrando os limites da humanização da linguagem maquínica.

Palavras-chave: poesia; automação; pós-humanização.

\section{ABSTRACT}

If post-humanism interrogates the exceptionality of the human, and if, on the other hand, verbal language is an expression of such exceptionality, then the post-humanization of language reveals a fundamental tension: understood as the externalization and automation of verbal language by means of computational devices (programmed to generate linguistic utterances in a relatively autonomous way), the post-humanization of language disturbs not only the centrality of the human, considered in the framework of the Enlightenment

\footnotetext{
* Centro de Literatura Portuguesa, Universidade de Coimbra, Portugal. ana.marques.silva@gmail.com https://orcid.org/0000-0002-7644-501X
} 
tradition, but also the notion that language is an exclusively human phenomenon. This article reflects on automatically generated language from the perspective of literary studies and draws on some of the central questions that emerge from the cross between cybernetics, language and literature. What happens to language when it is algorithmically processed and generated? How can the processes of symbolic representation and production be thought of in the context of artificial linguistic agents? When and how does an automatically generated text become a poem? By means of the analysis of a poetic experiment that can be considered as post-human, in the sense that it makes use of algorithmic tools and processes for the generation of language, we will highlight some of the tensions between computational devices and authorial writing, questioning the possibility or the impossibility for the literary to enroll in the cybernetic field of automation and demonstrating the limits of the humanization of machinic language.

Keywords: poetry; automation; post-humanization.

O que é um ciborgue? Um ciborgue é um organismo cibernético (cybernetic organism), uma entidade híbrida, composta por elementos orgânicos e nãoorgânicos ${ }^{1}$. O termo foi cunhado nos anos 60 por Manfred Clynes e Nathan S. Kline e, em 1984, Donna Haraway desenvolveu o conceito para designar a fluidez e o continum num espectro, desconstruindo o binarismo. O que é, então, um texto ciborgue? $\mathrm{O}$ texto generativo, na medida em que é um texto híbrido, composto por linguagens verbais e computacionais, por modalidades cognitivas humanas e algorítmicas, adequa-se de modo particularmente ajustado à noção de textociborgue. Aim Bad² (2015) é um exemplo daquilo a que Jhave chama de poesia ciborgue: o autor programa um gerador que produz textos, os quais são 'treslidos' em voz alta à medida que vão sendo gerados, tornando-se esta leitura uma forma de escrita. Esta é uma forma poética híbrida não apenas por ser generativa mas também porque nela a escrita e a leitura se confundem.

Aim Bad é um "Spreedr" (speed screen reading), uma forma poética desenvolvida por Jhave no contexto do seu projecto Big Data Poetry (BDP), iniciado em 2011 e presentemente em curso, o qual consiste numa investigação sobre criação literária com recurso a técnicas de "machine learning", nomeadamente redes neuronais artificiais $^{3}$. Desde 2016, o projecto BDP explora modelos algorítmicos programados

1. Entende-se os termos 'orgânico' e 'não-orgânico' como referentes a matéria viva e matéria não viva.

2. Um registo videográfico do processo de geração do poema está disponível em: https://vimeo.com/ 122828750

3. "Machine learning", ou aprendizagem maquínica, é um ramo das ciências computacionais que permite que um programa "aprenda" de forma autónoma, sem seguir instruções específicas, com base na análise estatística e na inferência de dados. Os processos de aprendizagem maquínica baseiam-se na análise de quantidades massivas de dados e no facto de o código não ser corrigido em face de resultados não correspondentes às espectativas implicadas na programação. Como resultado desta abordagem generativa à programação (baseada na autonomia algorítmica), os programas tornam- 
por Jhave com recurso a Pytorch (um framework ${ }^{4}$ em Python ${ }^{5}$ ), Tensorflow e Keras (bibliotecas open source para redes neuronais). No repositório GitHub do autor, encontramos todo o código usado nas suas experiências literárias ${ }^{6}$. Para o processo de geração, as redes neuronais são treinadas num corpus com 600.000 versos de poesia - da época romântica às vanguardas do século XX —, e os modelos bem sucedidos são posteriormente programados para gerar poemas em loop infinito. O processo de treino das redes neuronais é comparado por Jhave ao processo de fermentação: uma rede neuronal analisa um dado corpus e necessita de um intervalo de tempo para processar as relações abstraídas desse corpus e daí inferir um modelo. Os resultados da geração de texto por um modelo que tenha feito uma leitura de um dado corpus são diferentes dos resultados de um modelo que tenha feito diversas leituras do mesmo corpus:

Mead recipe: dilute honey with water, stir twice a day, wait. Fermentation begins after 24-48 hours. After a week, the fermented honey-wine (mead) can be enjoyed green, low in alcohol yet lively with essence. Or you can let it continue.

Generative-poetry recipe: text-corpus analysed by neural net, wait. After each reading of the corpus (a.k.a. 'training epoch'), a neural net can produce/save a model. Think of the model as an ecosystem produced by fermentation, an idea, a bubbling contingency, a knot of flavours, a succulent reservoir, a tangy substrate that represents the contours, topology or intricacies of the source corpus. Early models (a model is usually produced after the algorithm reads the entire corpus; remember, each reading of the corpus is called an epoch; after 4-7 epochs the models are still young) may be obscure but are often buoyant with energy (like kids mimicking modern dance). (...)

Eventually fermentation processes halt. In the case of mead, this may occur after a month, with neural nets, a process called simulated annealing intentionally decreases the learning rate every iteration; so the system begins by exploring large features then focuses on details. Eventually the learning rate diminishes to zero. Learning (fermentation) stops. ${ }^{7}$

O resultado destas operações é uma avalanche de linguagem desarticulada e incoerente, usada pelo poeta como matéria-prima sobre a qual o processo de criação poética se desenrola:

se opacos para os próprios programadores. Ao contrário da programação tradicional, em que um programa segue, passo a passo, instruções explícitas, na aprendizagem maquínica o programador não codifica instruções num algoritmo, mas antes "treina" esse algoritmo: para uma rede neuronal artificial reconhecer um gato, o algoritmo não segue instruções para identificar as partes que compõem a imagem de um gato (bigodes, olhos, orelhas, pelo, etc.), mas antes dá como referência ao algoritmo milhares ou milhões de imagens de gatos das quais aquele infere um modelo.

4. Em programação, um "framework" é um tipo de software que oferece funcionalidades genéricas que podem ser selectivamente transformadas por código adicional escrito pelo utilizador, e que oferece modos estandarizados para desenvolver aplicações.

5. Python é uma linguagem de programação.

6. O repositório GitHub de Jhave está disponível em: https://github.com/jhave/Big-Data-Poetry

7. Citação retirada do sítio em linha do autor. Disponível em: http://bdp.glia.ca/fermentation/ 
The live poem output is now used as a projection in conjunction with spoken word performances. The Python-based terminal then becomes a site for writing by the machine, reading by the human poet who must attempt to stitch and weave together poems from the incoherent hybrid yet often astonishing word-debris. ${ }^{8}$

A expressão "word-debris" é em si mesma significativa: a escrita da máquina é o resultado do processo de sondar um extensíssimo corpus de versos, frases, palavras que são respigadas pelo gerador (o modelo de rede neuronal artificial) e associadas entre si em função dos padrões (ou das probabilidades de ocorrência e associação) que o gerador reconhece no corpus e que extrapola para a sua própria escrita. O trabalho do gerador é um trabalho de reciclagem, realizada em função de critérios que são inferidos do corpus (padrões), e baseia-se na análise e na concatenação de palavras. Entre esta proto-linguagem gerada algoritmicamente e a expressão poética há, portanto, um fosso. A este propósito diz-nos Jhave:

Poetry is both the easiest and the hardest to generate. Since non-linear deflections and wordriffs are an aspect of contemporary poetry, slamming together ripe fertile conjunctions is easy. Migrating toward a sensitive, complex, experiential and contextual lived poetry is the real challenge ${ }^{9}$.

Para que a massa de linguagem gerada se torne significativa, são necessárias outras camadas de trabalho. É nessa passagem entre uma amálgama proto-textual e a possibilidade de emergência de um texto poético, capaz de gerar experiências de leitura significativas de um ponto de vista sensível ou experiencial, que entra a mão humana. Assim, o texto final, ou o texto que nos chega enquanto leitores, não consiste na linguagem gerada automaticamente, mas na leitura, não linear e em voz alta, que Jhave faz desse proto-texto gerado.

E nesse passo, ao ler, o autor está a escrever. A ideia de que o texto só existe na leitura é aqui levada à letra. A emergência do texto, enquanto inscrição legível, só acontece no momento da leitura de Jhave e, assim, é a leitura que produz a escrita, fazendo convergir no acto de escrita as categorias 'autor' e 'leitor'. A escrita coincide com a leitura ou, se quisermos, é a leitura que produz a escrita. Esta leitura caracteriza-se por ser rápida, improvisada e em tempo real (à medida que o gerador escreve), seleccionando intuitivamente palavras, transformando-as e tecendo um segundo texto (oral) a partir do texto gerado automaticamente (escrito). Ao ler, o autor atravessa rapidamente os textos gerados, ziguezagueando entre palavras num processo que obedece àquilo a que Jhave chama de "intuição":

8. Citação retirada do sítio em linha do autor. Disponível em: http://bdp.glia.ca/about/

9. Citação retirada do sítio em linha do autor. Disponível em: http://bdp.glia.ca/markov-bern/ 
One of the ends of digital literature is an external intuition.

External intuition is an engineering problem.

Intuition in this case is me.

Skidding thru the generated poems as they augment my imagination.

I call this act of augmented imagination: cyborg/skid/ spreedr poetry. (2015)

Um dos aspectos que caracterizam o projecto Big Data Poetry é a relação de colaboração humano-máquina, já que o gerador produz blocos de linguagem sobre os quais o poeta trabalha. A 'máquina' (entendida enquanto computação) é uma prótese para a "imaginação aumentada" do autor ou, como dizia o ciberpoeta português Pedro Barbosa já em 1996, é um "telescópio de complexidade". Aliás, para Jhave, este é, a curto prazo, o futuro da escrita: "um assistente computacional para uma intenção criativa de explorar o espaço-recurso topológico de frases potenciais $^{\prime 10}$. Podemos considerar que, independentemente das diferentes poéticas de diferentes autores, a computação entra em cena na poesia generativa e combinatória como uma ferramenta técnica que expande a criatividade autoral. O trabalho do poeta divide-se em dois momentos: o da meta-escrita, e o da escrita pela leitura. O primeiro corresponde à programação, enquanto que o segundo corresponde à leitura que inscreve o poema num espaço aural digitalmente mediado. Esse trabalho afasta-se do paradigma da escrita (entendida como inscrição gráfica, percepcionada visualmente) na medida em que se situa na oralidade e no improviso, aproximando-se o seu resultado da "spoken word" ou das cantigas populares à desgarrada"1 , por exemplo, e, desse modo, é com o proto-linguajar das máquinas que o poeta interage.

Este objecto poético, enquanto texto, é composto por 3 camadas diferentes: 1) a escrita do código; 2) o resultado da geração; e 3) a leitura desse resultado. O código (a $1^{\text {a }}$ camada) é um arqui-texto, não no sentido proposto por Gérard Genette (o conjunto de categorias que precedem o texto e o situam numa grelha, como os tipos de discurso ou géneros literários), mas no sentido de que o código controla a inscrição do texto gerado numa superfície. O texto gerado, por sua vez, é um proto-texto (porque ainda não é o texto final), e o texto final consiste na leitura feita por Jhave. A segunda e a terceira camadas de trabalho (geração maquínica e leitura humana) sobrepõem-se no momento performático, que é a dimensão em que a obra, enquanto tal, se expressa e existe. Este é um aspecto que distingue o

10. Disponível em: http://bdp.glia.ca/pytorch-poetry-generation-pre-wordhack-epoch-16-video/

11. As cantigas populares à desgarrada, ou cantares ao desafio, são um género musical tradicional português, da região do Minho. Consistem num duelo improvisado entre dois cantadores (e/ou cantadeiras), em que cada um responde ao outro, alternadamente, em quadras. O primeiro verso da quadra de resposta repete o último da quadra anterior. 
projecto BDP dos restantes estudos de caso em análise neste estudo, nos quais a autonomia e a subjectividade do autor se plasmam na programação e/ou na fixação do resultado automaticamente gerado.

Em Aim Bad, a obra é um acontecimento performático. A escrita do código e o resultado da geração automática são as estruturas que permitem a emergência desse acontecimento. $\mathrm{O}$ processo criativo não consiste apenas na composição formal de um programa que explora uma ideia, antes se prolonga e desdobra na acção improvisada, na acção sensível sobre as formas no momento da geração propriamente dita. Assim, e nas palavras de Ricardo Guerreiro (2015), compositor português que trabalha no contexto da música electroacústica generativa, "a situação interactiva, tal como a propomos, vê no par composição-performação o seu objecto final" (p. 90), rejeitando "a ideia de reduzir o processo criativo a procedimentos meramente formalistas" (p. 107). A palavra final pertence à esfera da expressão do autor que manipula as formas geradas em performance de acordo com a sua subjectividade. Essa manipulação improvisada constitui-se como objecto artístico, promovendo "a indistinção de processo e de produto" (p. 111). Se a geração automática introduz uma forma radical de mediação técnica, neste caso é na performance improvisada sobre as formas geradas que o controlo autoral é recuperado. $\mathrm{Na}$ medida em que mesmo este texto final se instancia como um fluxo efémero de escrita e de vocalização da escrita, trata-se de um texto condicional e fluido, indiferente a qualquer fixação.

Poderemos falar de inscrição no contexto da oralidade? Não, mas sim: no caso de Aim Bad, as palavras são pronunciadas, existem como instâncias breves e efémeras, suspensas no ar, encadeadas umas nas outras, cada uma aparecendo e desparecendo no tempo presente-já-passado à medida que o poeta improvisa o poema. Esta fala é transiente, flui, pertence ao domínio da performance, mais do que do literário entendido enquanto letra inscrita, letra da memória, da história ou da lei. Por um lado, não podemos falar de inscrição porque as palavras ditas não são fixadas numa superfície (tangível ou virtual: na página, no disco rígido ou na rede). De algum modo, podemos dizer que falar é escrever no ar. Ora, o ar, sendo uma 'superfície' etérea, não permite a fixação. E será que a impossibilidade de fixação invalida a inscrição? Não podemos pensar numa inscrição tão efémera quanto o momento que ocupa no tempo? Ouvir a fala, ou a leitura aural, é, assim, como ouvir música: ler o som é concentrar a atenção em marcas sonoras que se propagam no ar, anotando e discretizando o tempo. Podemos também considerar a oralidade enquanto inscrição no sentido em que a fala, tal como a escrita, é uma forma de externalização da linguagem. 
Mas como se lê a fala? Como se inscreve a voz num campo de leitura? A voz humana é plástica e instantaneamente identificável. As variações prosódicas e estilísticas (timbre, entoação, dinâmica) são aspectos expressivos que a voz humana articula na mais fina subtileza. Distinguimos na voz humana uma enorme panóplia de variação que se expressa ao nível da fala, e não da língua. A percepção de que uma dada voz é um quem e não um quê tem a ver com o sinal, e não com a semântica. Reconhecemos a voz humana numa língua estrangeira, por exemplo. A respiração e os sons do aparelho fonador, bem como as inflexões associadas à subjectividade situam a voz num contexto, ligando-a ao corpo, àquilo que excede a digitalização fonológica do som produzido. Barthes falou no grão da voz (1973) precisamente para se referir à textura, à especificidade ou ao excepcionalismo expressivo de cada voz. O som da voz dá à linguagem uma forma material específica, um sopro e um corpo tangível no espaço sonoro. Associamos a voz ao eco ou à presença, ausente $\mathrm{e}$ mediada, do autor. A voz é assim um veículo de mediação que recodifica a presença ausente de uma alteridade.

Com o desenvolvimento das tecnologias digitais de processamento de linguagem, a capacidade de replicar artificialmente a voz humana torna-se uma realidade, e as diferenças sensíveis entre uma voz gerada artificialmente e uma voz humana vão-se esbatendo, aumentando a crescente indiferenciação entre realidade e simulacro. Mas em Aim Bad, é da voz do autor que se trata. Aqui, a voz da máquina só pode ser pensada como o conjunto de instruções programadas pelo autor e, nessa medida, é também a voz autoral que está em causa.

No entanto, em comparação com o que acontece nos processos combinatórios e generativos desenvolvidos em décadas prévias ao advento de tecnologias de aprendizagem maquínica, entre a programação do autor e a geração há um fosso ainda maior: a aprendizagem computacional cria uma camada adicional de mediação que aumenta a distância entre o programa e o seu resultado, aumentando também a distância do autor relativamente ao código e à escrita. Uma vez que as redes neuronais são agentes autónomos e generativos que operam a uma escala incompatível com a percepção humana, as suas operações não são perscrutáveis pelos seus programadores. Por isso, ainda que a voz autoral se inscreva, neste caso, na leitura do resultado textual produzido e a sua intencionalidade esteja presente na conceptualização dos dados e dos algoritmos, a presença, controlo e autonomia do autor estão aqui significativamente mais ausentes do que nos casos em que o código é explícita e integralmente manipulado pelos programadores meta-autores. Podemos por isso afirmar que a autonomia da máquina (que permite os processos de aprendizagem) aumenta na proporção em que diminui a autonomia do autor. 
Neste sentido, e ao contrário do que creem os engenheiros, a aprendizagem computacional é um processo de desumanização das máquinas e não um processo de humanização, já que as afasta cada vez mais da escala humana, emancipando-as progressivamente.

Ao ler com um certo grau de improviso aquilo que a máquina gera e apresenta (a um ritmo superior ao ritmo humano de leitura), Jhave coloca-se na posição de mediador, permitindo-nos escutar a "fala" da máquina e explicitando, através da sua voz e da sua leitura, a estranheza da pós-linguagem cibernética. Podemos por isso perguntar até que ponto o poeta, mais do que um explorador da potencialidade da geratividade linguística (citada acima como "espaço-recurso topológico de frases potenciais"), não se tornará um apêndice orgânico do dispositivo cibernético a partir do momento em que a sua voz se torna o corpo que inscreve a linguagem ciborgue num espaço humanizado de leitura.

Nesta experiência poética, como vimos, a voz entra em cena como mediadora da escrita. A voz que escreve sobrepõe-se à escrita automática, como um molde orgânico e dinâmico que desce sobre uma massa digital, seleccionando e compondo o texto dito através da intuição. Porquê a intuição? O que é a intuição? Para Bergson, pensar intuitivamente é pensar em termos de duração, de movimento e mudança:

To think intuitively is to think in duration. (...) Intuition starts from movement, posits it, or rather perceives it as reality itself, and sees in immobility only an abstract moment, a snapshot taken by our mind, of a mobility. (...) For intuition the essential is change (2007 [1946], p. 22).

A intuição passa pelo movimento de duração e mudança das formas num intervalo de tempo. A rapidez da geração automática induz precisamente esse carácter temporal na leitura de Jhave. A rapidez da geração produz rapidez na leitura, eliminando o espaço para a hesitação. Essa rapidez associada à intuição é por isso aqui explorada como um constrangimento criativo de escrita.

Esta leitura que escreve é sem rede. Ser sem rede implica imediatez, ausência de filtro. É curioso que a questão da autenticidade surja no contexto da poesia automática, frequentemente entendida como uma forma de escrita "artificial", "fria" ou "desprovida de humanidade". De facto, a literatura generativa sublinha precisamente o humano na relação humano-máquina, assinalando a sua dissolução e insistindo, por isso, na posição determinante do autor face ao texto gerado. Em Jhave encontramos uma poética que evidencia a intuição humana elevando-a à última camada da composição, a qual é entendida como fase de acabamento, de afinação ou de refinamento, e é na leitura improvisada de um texto gerado, sobre o qual o autor não tem controlo algum, que a autoria é reclamada. À medida que os 
sistemas de geração se tornam cada vez mais complexos e opacos, afastando-se cada vez mais da escala humana, a autoria tende a inscrever a sua autonomia e controlo sobre a linguagem, adicionando camadas de trabalho sobre a geração automática.

Em Aim Bad, a rapidez induzida por uma leitura improvisada coloca precisamente em evidência os aspectos que escapam à computação (a ambiguidade ou a ausência de uma lógica matemática), reforçando o lugar desses aspectos na criação poética. Podemos também pensar na imediatez da comunicação na sociedade contemporânea, na instantaneidade da cultura dromológica. O que acontece quando a temporalidade da automação se cruza com a temporalidade do humano? Acontece o que vemos em Aim Bad: é impossível acompanhar o ritmo da geração senão confiando na intuição para transformar e relacionar frases e palavras. Nesta modalidade de expressão e de atenção não há erro, só acaso e deriva que é integrada sem hesitação no corpo textual que vai sendo composto. Esta leitura rápida e improvisada dá ao texto ritmo e rima, métrica e entoação, e até mesmo campos semânticos que vão surgindo lentamente, à medida que o tempo passa. Da massa de linguagem crua e relativamente desconexa que a máquina produz a alta velocidade, emerge um tecido (textum) que resulta da selecção feita pelo poeta que adopta a velocidade da geração artificial para explorar a sua própria intuição e atenção. $\mathrm{O}$ gerador é um instrumento não exactamente de escrita, na medida em que o texto final não é o produto da geração, mas um instrumento criativo que potencia a exploração e a expressão de modos cognitivos e criativos próprios de seres vivos: a atenção, a intuição, a expressão de uma sensibilidade.

A rapidez da geração, que é determinada pelo autor, determina também a leitura no sentido em que produz concentração e imersão. De facto, o exercício de Jhave é exigente do ponto de vista do manter a atenção e o ritmo de leitura a uma velocidade elevada. Ao assistir à performance de Jhave ou, em alternativa, ao vídeo disponibilizado pelo autor, apercebemo-nos facilmente do esforço de concentração implicado na leitura intuitiva da avalanche de linguagem gerada. Em certa medida, esta leitura produz o encantamento que sempre se associou à poesia, oral ou escrita, um encantamento que resulta da concentração da atenção nas palavras ditas, nas suas densidades, lastros e aspectos melódicos, rítmicos ou harmónicos. Os efeitos sonoros (musicais) que acompanham a voz do autor contribuem também para esse efeito.

Importa anotar que o texto produzido pela leitura de Jhave é tão desconexo quanto o texto gerado pelos algoritmos. $\mathrm{O}$ que a leitura produz não é sentido, mas forma e presença, ambiguidade e latência, precisamente a matéria da poesia. $\mathrm{O}$ que está em causa nesta experiência é a plasticidade formal da linguagem enquanto 
matéria de composição, explorando os efeitos sonoros e a expressividade dos choques entre palavras desconexas. Para este efeito de expressividade assémica contribui a temporalidade: pela sua natureza rápida e radicalmente transiente, em que a oralidade reforça a fluidez que, por regra, associamos ao texto generativo, os Spreedrs de Jhave resistem à interpretação.

No site que documenta o projecto BDP podemos constatar, pela lista de entradas recentes ${ }^{12}$, que o poeta experimenta diferentes velocidades de geração, as quais determinam, por sua vez, as diferentes velocidades de leitura. Mas além da dimensão temporal, há outros aspectos da geração que o poeta manipula no seu jogo experimental de escrita ciborguiana, como a temperatura, um parâmetro em redes neuronais que influencia o grau de aleatoriedade implicada nos processos generativos ${ }^{13}$. Estas variações demonstram como a manipulação dos parâmetros de geração se constitui como parte integrante do processo de escrita, entendida como composição. O poeta ajusta o código que gera linguagem como um músico que trabalha com sintetizadores ajusta os efeitos que canalizam e processam a matéria sonora. Neste caso, a manipulação da velocidade e da temperatura com que o gerador escreve são alguns dos mecanismos através dos quais a autoria se realiza.

Outro aspecto fundamental que caracteriza algumas das experiências no projecto BDP é o facto de a leitura de Jhave ser sujeita a um processamento algorítmico que fecha o circuito de comunicação num 'loop': à medida que Jhave lê em voz alta, a sua fala é novamente transformada em escrita por via de um software de reconhecimento de voz que processa as palavras ditas, reinscrevendoas na lógica computacional através da transcrição automática. Este fechamento do circuito de geração (artificial e humana) de linguagem não implica a perda da autoridade ou autonomia do autor, pelo contrário, já que a linguagem que Jhave devolve ao sistema é uma linguagem trabalhada pelo poeta, através da intuição e do improviso, contaminando com a sua voz o campo de linguagem onde o gerador se move - voz essa que ganha a possibilidade de se inscrever e se fixar através da transcrição automática que transforma a fala em escrita. Mas esta é uma transcrição 'tosca', cega ao contexto e às nuances, como 'toscas' são ainda (mas não por muito tempo, dado o progresso exponencial das tecnologias de processamento de linguagem) as traduções automáticas. Esse texto 'tosco' é o resultado dos processos interpretativos maquínicos que, ao contrário dos processos interpretativos humanos,

12. Ver sítio em linha do autor: http://bdp.glia.ca/

13. Na seguinte entrada do seu sítio pessoal, o autor esclarece em que consiste a 'temperatura' e oferece um exemplo de experiência poética com variações neste parâmetro. Disponível em: http:// bdp.glia.ca/brerin-2-hours-at-random-temp/ 
não são hermenêuticos nem semióticos, no sentido da semiose humana e dos sistemas de sinais que organizam a vida social, apesar de não deixarem de sê-lo no sentido em que consistem na conversão e transmissão de sinais. A humanização que o poeta opera na linguagem gerada pelas redes neuronais imiscui-se nos circuitos maquínicos através do processo de transcrição automática que se inscreve na rede essa superfície de escrita lamelada, composta por camadas, distribuída e incontida.

Manuel Portela considerou a escrita gerada por redes neuronais no project BDP como uma forma de "poem mining":

Now that automated constrained processes are able to collect and generate endless snippets of language and thousands of poems per hour, poem-mining can still be offered to a human voice for stitching and improvisation. "Reading along with the machine" is, perhaps, the only possibility of overwriting its writing constraint (2017).

Tal como os processos de "data mining" ${ }^{14}$ consistem na análise de bases de dados particularmente vastas com vista à extracção de informação em função da descoberta de padrões e anomalias, também os processos de lecto-escrita maquínica explorados por Jhave consistem na inferência de formas extrapoladas da análise de um corpus demasiado extenso para a análise humana. $\mathrm{O}$ que Jhave faz é humanizar esse processo algorítmico através de uma operação que inventa uma linha, um fio que desenha, no pano de fundo da linguagem gerada, um bordado, uma forma sensível. Podemos, aliás, encontrar duas camadas de extração, ou de mineração: a primeira, da máquina que escreve em função da leitura que faz de um corpus, e a segunda, do poeta que escreve através da leitura que faz da linguagem gerada. $\mathrm{O}$ poema é o resultado do segundo processo de extração, aquele que o poeta opera sobre a linguagem gerada, através da leitura vocalizada. O facto de a voz ser o medium de escrita do poema é significativo não só no sentido em que é pela voz que o poeta humaniza o campo de linguagem algorítmica (fazendo poesia a partir de "big data"), mas também no sentido em que a voz, tal como o olhar, liga o dentro ao fora como um túnel ou uma via rápida. A voz do poeta é o poeta nu.

Curioso é também notar como este processo de refinamento que atravessa diversas fases (as épocas de leitura e aprendizagem levadas a cabo pela máquina, e o acabamento final levado a cabo pela voz do poeta) é incompleto, no sentido em que fica num estado imperfeito, como uma gema não inteiramente lapidada que mantém as marcas da origem - neste caso uma origem híbrida, cujas marcas são visíveis no processo final, tanto através da persistência do não sentido da linguagem gerada

14. 'Data mining', ou mineração de dados, é o processo computacional de descoberta de padrões em grandes quantidades de dados, através de métodos que incluem aprendizagem maquínica, estatística e bases de dados. 
pela máquina, como através do aspecto improvisado da leitura de Jhave. A camada final de acabamento é inacabada e 'inacabável', porque viva e mutável. Essa camada final é um acabamento imperfeito, e nessa medida, puro, no sentido em que reflecte uma essência, essa essência que tinge a voz.

Os Spreedrs de Jhave, bem como todo o seu projecto BDP, são uma forma de poesia generativa que extrai sentido e expressividade poética da densa massa de informação em que as máquinas actuam, manipulando as ferramentas de escrita algorítmica e manipulando também a linguagem processada por essas ferramentas. Esta é, por isso, uma forma de escrita ciborgue, tal como definida por Donna Haraway:

Cyborg writing must not be about the Fall, the imagination of a once-upon-a-time wholeness before language, before writing, before Man. Cyborg writing is about the power to survive, not on the basis of original innocence, but on the basis of seizing the tools to mark the world that marked them as other. (1991, p. 175)

Longe de reclamar um paraíso perdido que nunca existiu, a poesia ciborguiana de Jhave utiliza as ferramentas através das quais a automação reconfigura o mundo, escrevendo auralmente por cima da sua escrita. Ao mesmo tempo, esta experiência poética demonstra a impossibilidade de humanizar a linguagem maquínica: a estranheza dos poemas improvisados com que Jhave retroalimenta o sistema computacional demonstra que a humanização da linguagem gerada maquinicamente não permite que a linguagem se organize de forma a produzir sentido. Tosca e incompleta, rápida e quase ilegível, a poesia minerada por Jhave nos detritos linguísticos do espaço cibernético ilumina o desfasamento entre autor e rede neuronal, entre a organicidade e a digitalidade, demonstrando a irredutibilidade da poesia ao processamento maquínico e reforçando o lugar da autoria no sistema textual.

\section{REFERÊNCIAS}

BARBOSA, Pedro \& CAVAlHEIRO, Abílio. (1996), Teoria do Homem Sentado, Porto, Edições Afrontamento.

BARTHES (1973), Le Plaisir du Texte, Paris, Editions du Seuil.

BERGSON, Henri (2007), The Creative Mind: An Introduction to Metaphysics [1946], Transl. Mabelle L. Andison, N.Y., Dover Publications. 
GUERREIRO, Ricardo (2015), Redes Mediadas por Computador na Composição e Performação de Situações Musicais Interactivas, Tese de Doutoramento em Ciência e Tecnologia das Artes, Universidade Católica Portuguesa. Acedido a 19.05.2019: https://repositorio.ucp. pt/bitstream/10400.14/19353/1/RicardoGuerreiro_Disserta\%C3\%A7\%C3\%A3o. pdf

Jhave (2015), "ELO 2015 - Bergen - Performance", BDP: Big Data Poetry. Acedido a 19.05.2019: http://bdp.glia.ca/elo-2015-bergen-performance/

PORTELA, Manuel (2017), "Writing under constraint of the regime of computation", The Bloomsbury Handbook of Electronic Literature, Tabbi, Joseph (Ed.), Bloomsbury Academic

HARAWAY, Donna (1991), "A Cyborg Manifesto: Science, Technology, and Socialist Feminism and the Privilege of Partial Perspective", Simians, Cyborgs and Women: The Reinvention of Nature [1984], London, NY, Routledge. Acedido a 19.05.2019: https:// monoskop.org/images/f/f3/Haraway_Donna___Simians_Cyborgs_and_Women The Reinvention of Nature.pdf

Recebido: 20/05/2019

Aceito: 4/07/2019

Publicado: 12/07/2019 